\title{
Introduction to Internal Crowdsourcing: Theoretical Foundations and Practical Applications
}

\author{
Hannah Ulbrich, Marco Wedel, and Hans-Liudger Dienel
}

The research landscape in the area of forecasting and assessing working conditions has become increasingly difficult to understand. There are plenty of identified reasons, drivers and catchwords to describe a systemic transformation. Individualand subject-specific approaches to describe and understand the changes to work are being developed in almost every scientific discipline, as well as by (economic) associations and actors in the sociopolitical spheres. Despite all complexity and contradictions, 'digitalization' seems to be one focal point when it comes to identifying independent variables to explain the 'future of work'. The corresponding discussions, analyses, recommendations and scenarios can be found under the well-known headings 'Work 4.0', 'Industry 4.0', 'Education 4.0', 'Society 4.0', etc. In addition to systemic descriptions, oftentimes dominated by economics and business management approaches, there are changing individual, subject-inherent perceptual understandings indicating a change in social values with regard to work and its function. Ultimately, for the majority of the population and the (welfare) state, work remains the necessary prerequisite for financially securing their livelihoods.

This brief contextualization shows the burdensome complexity of the overall research field. Bearing this complexity in mind, when seeking to approach the topic in a constructive way, it is neither meaningful nor possible to choose research foci that try to understand the digitalization of work. To avoid banality and generalizations, it is important to differentiate within the overall subject matter and arrive at concise and manageable research subjects.

H. Ulbrich $(\triangle) \cdot M$. Wedel

Technische Universität Berlin, Institute for Vocational Education and Work Studies, Berlin, Germany

e-mail: hannah.ulbrich@tu-berlin.de; marco.wedel@tu-berlin.de

H.-L. Dienel

Technische Universität Berlin, Center for Technology and Society, Berlin, Germany

e-mail: dienel@ztg.tu-berlin.de 
Such an approach has been instigated by the German Federal Ministry of Education and Research (Bundesministerium für Bildung und Forschung-BMBF). At the beginning of 2015, the Ministry announced guidelines for funding measures with the research focus 'work in the digitalized world' within the framework of the R\&D programme 'the Future of Work' as part of the umbrella programme 'Innovations for Tomorrow's Production, Services and Work'. The initially broad aim has been to explore the possibilities of digital technologies and to develop and disseminate solutions for working in the digital world. The resulting research programme 'Transformation of Work Through Digitalization' (TransWork) declared that its central goal would be to examine the effects of digital technologies on employment and labour markets, health protection and business organization and to develop and disseminate approaches to solutions for working in the digital world. Respective research projects where expected with the aim of analysing and evaluating current research fields in the design of work (competence development, mastering complexity, productivity management and the design and regulation of work) and changes brought about by digitization while disseminating examples of designs for 'good work' for specific target groups (BMBF 2015; TransWork 2017).

To narrow down this still broad approach, five focus groups consisting of individual research projects have been created: 'Assistance Systems and Competence Development', 'Project and Team Work in the Digitalized Working World', 'Productivity Management', 'Work Design in the Process of Digital Change' and 'Designing Work-Networks and Flexibility' (TransWork 2017).

The research project 'Internal Crowdsourcing in Companies' (Internes Crowdsourcing in Unternehmen-ICU) has been selected as part of the latter focus group. Its overall goal is to research approaches as to how good humane work can succeed under the changed conditions of network-bound, temporally and locally flexible work. The phenomenon of Internal Crowdsourcing in that context represents a concise and manageable research subject to inform reliable hypotheses on the digitalization of work with respect to the social component of sociotechnical systems (human-machine interaction is not the focus; machine-machine interaction is not meant). While the role and influence of Internal Crowdsourcing in the context of the digitalization of working environments is neither empirically nor theoretically well understood, ICU has been designed to lay down some initial theoretical foundations and foster an understanding of practical applications for an ongoing discussion.

\section{About the Research Project 'Internal Crowdsourcing in Companies' (ICU)}

Internal Crowdsourcing refers to the firm extending its problem-solving to a large and diverse group of self-selected contributors beyond the formal internal boundaries of a large firm; across business divisions, bridging geographic locations, levelling hierarchical structures. (Elin Byrèn 2013, p. 4) 
The basic idea of Internal Crowdsourcing is to mobilize and strengthen the internal exchange of knowledge and interaction within the company. The process is intended to directly promote problem-solving capacities through crossdepartmental and interdisciplinary thinking and collaborative action skills for cooperation between employees and between management and employees. Existing knowledge, both explicit, but above all also person-related implicit technical and experiential knowledge, the so-called sticky knowledge, can be quickly accessed within the company through the application of Internal Crowdsourcing and used to develop solutions, processes and decisions. By testing new communication and collaboration possibilities at low thresholds, in particular, Internal Crowdsourcing can make an important contribution towards an employee-friendly and more agile corporate culture for the digitalized working world. It touches upon aspects such as growing demands for participation by and of employees, the desire for flatter hierarchies including cross-company and cross-divisional communication channels, agile and modern working methods and organization, demands for the stronger democratization of companies as well as a basic corporate capability to survive in the working world of the twenty-first century (Industry 4.0, Work 4.0, Economy 4.0, etc.). Since IC changes or supplements the cross-company and cross-divisional communication possibilities, it creates new work and interaction spaces and enables the digital integration of employees while opening up space for design and experimentation with respect to the future organization of work.

While the above clearly hints at one potential for Internal Crowdsourcing to serve as a catalyst for establishing a digital working culture, it is astonishing that IC, both in research and in practice, has almost exclusively been treated as yet another tool for innovation management (Keinz 2015; Zhu et al. 2014, 2016; Zuchowski et al. 2016). Within the framework of the research project 'Internal Crowdsourcing in Companies' (ICU), that lens has been broadened for the first time by arriving at the wellfounded assumption that the method has further potential for use beyond its innovation-generating character, namely, for employee participation on the one hand and for employee qualification on the other.

\subsection{Employee Participation}

As an instrument for digital employee participation, Internal Crowdsourcing can give employees the opportunity to participate at different levels of the company. They are given the opportunity to contribute their personal experience and knowledge in the form of suggestions and ideas with regard to company processes and to help shape the working environment in a constructive manner. Through the technical mediation of the process, Internal Crowdsourcing achieves a high reach with little effort and opens up a fast and direct channel of communication within the company. In principle, employee participation, among other factors, contributes to a working atmosphere based on appreciation and recognition for all involved. 


\subsection{Employee Qualification}

In order to prepare employees for the new requirements presented by the ongoing digitalization in everyday work and to qualify them for new activities that arise in this context, companies must find new ways and measures to open up internal career development opportunities. Particularly since the introduction of the 'European Qualifications Framework' in 2008, there has been a recognizable shift in the academic and practice-relevant specialist debates from the 'hard' facts of qualifications certificates to the 'soft' indicators of abilities, skills and knowledge, i.e. competences. Although qualifications have of course lost none of their importance as a necessary indication of existing vocational skills, it is clear that they do not represent a guarantee that these skills will be implemented in practice. The competence approach has also been adapted in corporate practice, e.g. in connection with procedures for filling vacancies internally. In order to assess the actual 'skills' of employees who have already been hired, formal qualifications are usually of secondary importance, with an employee's competence profile being more meaningful. Furthermore, assessing competence in the company can also pursue the goal of determining the need for further training or of evaluating the learning situation as a prerequisite for independent/self-organized learning processes and for the necessary learning support (Metzger 2016, p. 10; Wegerich 2015; Melzer et al. 2019, p. 11).

Of course, the potential for product, service or process innovation through IC remains very high and should not be neglected as an important part of Internal Crowdsourcing.

\subsection{Project Objectives and Methodical Approach}

Against this background, the goal of the ICU research project has been to develop a cross-industry model in a multistage, iterative process that would serve as a reference case for good practice that is useful for future crowdsourcing activities. This so-called ICU model is composed of a process designed specifically for Internal Crowdsourcing, which, in addition to innovation management, strategically addresses the dimensions of employee participation and employee qualification, a process management system and an IC platform.

Based on analyses of operational IC implementations, scientific research and practical experience, a basic model was first designed and implemented as a pilot at the company collaboration partner within the project, the energy service provider GASAG AG (first iteration). This model has since then been optimized and transformed into the GASAG good practice example (second iteration). A crossindustry reference model has been developed based on the good practice example, the main features of which will be presented in this book.

The focus in the development process has been the employee-oriented design of the application of Internal Crowdsourcing. In order to take into account the different 
demands involved, we have applied a participatory approach to develop the ICU model together with all relevant stakeholders (employees/management and works council) and with the active support of the union to ensure proper consideration of the legal and political framework for the process. Furthermore, the guidelines for good digital work of the Enquete Commission Internet and Digital Society (2013) and the guidelines for good digital work of the DGB (2014) were also taken into account. By maintaining legal and social working standards, the aim has been to create a future-oriented and sustainable working environment as well as a better quality of work in the digitalized world.

The ICU model has been designed to primarily address companies that need orientation in their individual transformation process and are interested in using digital processes to mobilize their potential internal knowledgebase as well as existing competencies. Therefore, the practical experiences of digital champions, large RD\&D avers corporations and agile start-ups did not serve as a benchmark for the project but merely as an aspiration during the development process. According to a study on innovation in German companies (Pohlisch 2019) conducted as part of the project, the industry partner GASAG AG very much represents this cross-section of German SMEs in view of the challenges for competitiveness in the context of digitalization. With regard to innovation activities, though energy providers have below-average quotas, they are nonetheless exposed to strong adaptational pressure against the backdrop of the far-reaching upheavals taking place within the German and European energy system (Pohlisch 2019; Wedel 2016). Thus, the GASAG AG qualifies as a valid example with regard to the necessity of implementing innovationfacilitating procedures to ensure success and competitiveness and represents the ideal application case for the project objectives.

\subsection{Project Partners}

\section{Technical University of Berlin: Department of Vocational Education/Technol- ogy and Participation/Institute of Vocational Education and Work Studies (Fachgebiet Arbeitslehre/Technik und Partizipation/Institut für Berufliche Bildung und Arbeitslehre)}

The Institute of Vocational Education and Work Studies at the Technical University of Berlin has existed since the year 2000 and is composed of the Department of Technical Didactics of the Vocational Disciplines and Work Studies, the Department of Vocational Education/Technology and Participation and the Department of Economic Education and Sustainable Consumption. The Department of Vocational Education/Technology and Participation has three main areas of research:

- In the field 'technology and participation', participative methods that involve school pupils, customers and citizens in the process to develop new technological products and services are being evolved. This participative product development 
is still in its infancy. New methods of political citizens' participation in the development of technology are being translated.

- In the field 'technology and education', definitions and images of technology are being developed, knowledge and abilities are being compared, and new understandings of technology are being applied in WAT lessons as well as more generally to technological education.

- In the field 'future of technology', historic and present visions of technology are being compared, and sustainable scenarios and models are being developed, in order to contribute these to future applied academic research.

\section{Technical University of Berlin: Quality and Usability Lab/ Institute of Software Engineering and Theoretical Computer Science (Quality and Usability Lab: Institut für Softwaretechnik und Theoretische Informatik)}

The Quality and Usability Lab offers courses on three layers: technology, interaction design and user. In the Quality and Usability Lab, students in electrical engineering, information technology and computer science learn to estimate the effects of the systems they develop on the user and are excellently prepared for interdisciplinary cooperation. Our long-term goals are to develop methods for measuring the quality and usability of information and communication technology, to establish a relationship between quality and usability and the technical characteristics of the systems and services, to derive guidelines for system and service design on that basis, to predict quality and usability-based system characteristics and to implement the described methods in the cycle of specification, planning, design, implementation, optimization and monitoring of new systems and services. We apply these principles, for example, to systems for transmitting speech, audio and video signals (telephony, voice-over-IP, radio, IP-based-television, telephone conferences, etc.), multimodal human-machine interaction (spoken dialogue systems, web-based services, multimodal dialogue systems, etc.), as well as-in a broader sense-all systems enabling multimodal interaction between humans, machines and the environment (virtual environments, augmented environments, context-sensitive systems, etc.).

\section{Technical University of Berlin: Department of Innovation Economics, Institute for Technology and Management (Fachgebiet Innovationsökonomik: Institut für Technologie und Management)}

The Department of Innovation Economics at the Institute for Technology and Management in the Faculty of Economics and Management at the Technical University Berlin has been headed by Prof. Knut Blind since 2006. Prof. Blind is also responsible for the innovation and regulation business unit at the Fraunhofer Institute for Systems and Innovation Research. In our teaching, we focus on the field of tension between theoretical models of innovation economics and their empirical application, alternating between prospects of economics and business studies. Our research covers a broad range of questions, especially relating to the influence that different institutional frameworks have on various forms of innovation. More specifically, our work includes the fields of standardization, intellectual property rights, 
regulation (e.g. concerning environmental, labour market or public procurement issues), open innovation, peer innovation and open source. Our mission is to foster responsible innovation research towards the achievement of the Sustainable Development Goals. The Department's research is spread within the global scientific community among policymakers, business representatives and civil society. The Department is an open platform connecting international researchers, students and practitioners.

\section{Institute for Future Studies and Technology Assessment (Institut für Zukunftsstudien und Technologiebewertung)}

The Institute for Future Studies and Technology Assessment is an interdisciplinary research and consulting institute. Future-oriented studies with long-term social significance and providing support to decision-makers in the areas of business, politics and society by contributing practical knowledge are the goals of the institute. In doing so, the Institute for Future Studies and Technology Assessment is committed to the principle of sustainable development. Future research and scenario building, the analysis and promotion of new technologies as well as the assessment and evaluation of their economic, political, ecological and social consequences are the main focuses of the Institute for Future Studies and Technology Assessment's work. Last but not least, the Institute for Future Studies and Technology Assessment stands for inter- and transdisciplinary future research as well as implementation orientation, participation and stakeholder integration.

\section{GASAG Group}

Founded in 1847 in Berlin/Germany, the GASAG Group today is a modern, nationwide energy service provider whose range of services has long since expanded beyond electricity and natural gas. The group of companies is intensively engaged in innovative technologies and is driving the expansion of renewable energy. It demonstrates this commitment with products such as the 'EcoPool' virtual power plant, energy solutions for entire neighbourhoods and comprehensive energy consulting. In contracting and bio-natural gas solutions, the GASAG Group is the market leader in the capital region and continues to provide impetus for the energy revolution along the entire energy process chain. For several years, the GASAG Group has been producing eco-electricity and biomethane in its own plants, the number of which it expanded for the first time in 2016 with a wind farm in Brandenburg.

\section{Social Technology Design Forum at the German Trade Union Confederation (DGB) in the District of Baden-Württemberg (Forum Soziale Technikgestaltung beim DGB Baden-Württemberg)}

The Social Technology Design Forum at the German Trade Union Confederation (DGB) in the Federal State of Baden-Württemberg was founded on 7 October 1991 in Stuttgart as a consultative network within the DGB for the Federal State of Baden-Württemberg and closely linked to various trade unions-in particular IG Metall, ver.di, IG BCE, GEW and DGB. The Social Technology Design Forum is an open network of more than 2900 men and women from works and staff councils, 
colleagues, shop stewards, employees, self-employed, freelancers and job seekers and young and old. The participants bring in expert knowledge and experience from companies and administrations, science and technology, trade unions and professional associations, universities and research institutions, industry and services, crafts and municipalities, educational institutions and social institutions and online communities and crowds and from the areas of art and culture. It sees itself as a building block that facilitates the transfer of knowledge and provides experience in the mediation of knowledge. In moderated processes, the Social Technology Design Forum wants to 'translate' complex technical expertise into the living world of working people and, conversely, to confidently transfer experience-based design requirements from the working world into science, research and development.

\section{Structure of This Book}

As mentioned above, this anthology on the subject of Internal Crowdsourcing in companies is the result of a research project of the same name. As such, it addresses the overall research theme 'Work in the Digitalized Work' by applying a concise research focus within the framework of network-bound, temporally and locally flexible work, in this case, the subject of Internal Crowdsourcing. In its entirety, and since the goal of the ICU Research Project has been to develop a cross-industry model that would serve as a reference case for good practice in future crowdsourcing activities, the anthology represents an employee-oriented, cross-industry reference model for good practice in Internal Crowdsourcing.

As has been clear from the very beginning, Internal Crowdsourcing is neither empirically nor theoretically well understood yet. Therefore, the research presented in this book is roughly divided into two major parts: one part that is mainly dedicated to theoretical foundations and the other that is mainly dedicated to practical applications. The theory part includes this chapter, "An Introduction to Internal Crowdsourcing", "Managing the Crowd: A Literature Review of Empirical Studies on Internal Crowdsourcing" and "Systematization Approach for the Development and Description of an Internal Crowdsourcing System" by Pohlisch, Ulbrich and Wedel, which introduce, discuss and present theoretical foundations for Internal Crowdsourcing in order to foster an understanding of it for the ongoing scientific debate and to design practical applications. In chapters "Design of a Process and Role Model for Internal Crowdsourcing" and "An Empirical Analysis of an Internal Crowdsourcing Platform: IT Implications for Improving Employee Participation", the authors Iskender, Polzehl and Schröter bridge the gap between theory and application by referring to empirical results from the research project (here with respect to IT implications) and extensive work experience (here with respect to 4600 women and men from works councils and staff councils, union representative bodies and the workforce) in order to derive general implications for IC applications in both theory and praxis. Finally, in chapters "Proposals for the Future of Internal Crowdsourcing: A Trade-Union-Based Approach", "Good Practice at GASAG- 
Group: Recommendations for the Application of Internal Crowdsourcing from a Business Perspective" and "The Living Group Works Council Agreement as Social Innovation: Internal Crowdsourcing in the GASAG Group", Porth, Schröter, Uhl and Göll compile practical insights derived during the application of Internal Crowdsourcing in a company by including management perspectives as well as trade union perspectives and by focusing on qualification and competence development in organizations. The book finishes by looking beyond the horizon of the research project. In chapter "The Use of Internal Crowdsourcing for Qualification and Competence Development in Organizations", Zinke-Wehlmann, Friedrich and Römer discuss how the theoretical foundations and practical applications presented in this book can be applied to the concept of social business. The articles in detail are:

\section{An Introduction to Internal Crowdsourcing}

Jakob Pohlisch

This chapter aims to provide the reader with an introduction to crowdsourcing in general and Internal Crowdsourcing in particular. First of all, the elementary principles of crowdsourcing are introduced, finishing with a definition that constitutes the basis for this book. Secondly, different crowdsourcing typologies are described to inform the reader about classifications of the phenomenon in the academic literature. Thirdly, the crowdsourcing process is outlined in order to clarify the general procedure of this new kind of work organization. Lastly, the concept is transferred to the intra-organizational context, providing a description and definition of the concept of Internal Crowdsourcing that represents the main topic of this book.

\section{Managing the Crowd: A Literature Review of Empirical Studies on Internal Crowdsourcing}

Jakob Pohlisch

The phenomenon of crowdsourcing is increasingly being addressed within academic literature. Companies utilize crowdsourcing to search outside of the companies' boundaries for solutions to internal problems, thus accessing the vast and diverse knowledge and creativity of people all over the world. More recently, a growing interest has emerged, which concentrates on the intra-organizational application of this phenomenon-Internal Crowdsourcing. While conventional internal innovation activities have mostly been concentrated within a few dedicated departments, this new approach helps companies to open up their innovation process to all employees. Internal Crowdsourcing can help companies bridge geographical distances, integrate new employees, predict the market success of products and create ideas for new businesses.

This chapter aims to provide a comprehensive overview of the existing empirical findings regarding the management of Internal Crowdsourcing. In this review, 28 papers covering more than 100 companies are analysed. They are based on more than 800 interviews, participant observations, action design research, surveys and datasets of internal innovation contests. The results of this review will help practitioners to design the management of Internal Crowdsourcing, based on existing implementations and lessons learned, helping them to unleash the full 
innovation potential of their employees, creating a valuable competitive advantage.

\section{Systematization Approach for the Development and Description of an Internal Crowdsourcing System}

Marco Wedel and Hannah Ulbrich

There is a need for both a scientific foundation and theoretical fundamentals to describe Internal Crowdsourcing systems with binding, consensus-based terminologies and descriptions. (How) Can the already described subcategories and aspects of an IC system be meaningfully referenced and placed in an orderly overall relationship? What must be added, if necessary and possible, to system descriptions? The present article concentrates on identifying existing descriptions and definitions in connection with systematization approaches for the development of an Internal Crowdsourcing system. Since the phenomenon itself eludes allocation to an exclusively dedicated scientific discipline, it seems appropriate to choose interdisciplinary approaches and to build on existing theoretical and terminological approaches from related sciences.

\section{Design of a Process and Role Model for Internal Crowdsourcing}

Hannah Ulbrich and Marco Wedel

The successful implementation of Internal Crowdsourcing (IC) in a company requires a precise description and definition of the personnel responsibilities for the various process levels and process components within each process phase of IC. As part of the research project 'ICU-Internal Crowdsourcing in Companies', we have developed a new role model for Internal Crowdsourcing based on the practical application of IC in the company GASAG AG, an energy provider located in Berlin/ Germany. The aim of this article is to present the main features of this role model. It is based on the roles of the agile Scrum model, because partial aspects of the Internal Crowdsourcing process and certain process-steering tasks have similarities with the procedure and task descriptions of Scrum. Scrum, as a mature and practice-proven set of rules with role descriptions, rules, events and artefacts, provides helpful implications for the design of an Internal Crowdsourcing role model as we will demonstrate in further detail.

An Empirical Analysis of an Internal Crowdsourcing Platform: IT Implications for Improving Employee Participation

Neslihan Iskender and Tim Polzehl

Crowdsourcing has become one of the main resources for working on so-called 'micro-tasks' that require human intelligence to solve tasks that computers cannot yet solve and for connecting to external knowledge and expertise. Instead of using external crowds, several organizations have increasingly been using their employees as a crowd, to exploit employee's potentials, to mobilize unused technical and personal experience and to include personal skills for innovation or product enhancement. However, understanding the dynamics of this new way of digital co-working from the technical point of view plays a vital role in the success of Internal Crowdsourcing, and, to our knowledge, no study has yet investigated the relationship between the technical features and participation in Internal Crowdsourcing in empirical terms. This paper therefore aims to provide a 
guideline for organizations and employers from the perspective of the technical design of Internal Crowdsourcing, specifically regarding issues of data protection, privacy and security concerns as well as task type, design, duration and participation time based on the empirical findings of an Internal Crowdsourcing platform.

Proposals for the Future of Internal Crowdsourcing: A Trade Union-Based Approach

Welf Schröter

The 'FST' personnel network 'Forum Soziale Technikgestaltung' (Forum for Social Forms of Technology) from the German Trade Union Confederation (DGB) of Baden-Württemberg has been examining the subjects of informatization of work and digitalization since 1991. More than 4600 women and men from works councils and staff councils, union representative bodies and the workforce and from large companies and small- and medium-sized enterprises, the manual trades as well as self-employed people have been involved in an exchange about their experiences in production and services and in administrations. Against this background, and drawing on the accumulated knowledge gained from experience, the following proposals for the future of Internal Crowdsourcing have been derived. The proposals represent a trade union-based approach.

Good Practices at GASAG Group: Recommendations for the Application of Internal Crowdsourcing from a Business Perspective

Florian Porth

Innovative and marketable products and services as well as maintaining innovation capacity are basic conditions for a company's economic success, and these present implicit challenges in adapting to twenty-first century needs. These success factors are endangered by silo mentalities, insufficiently pronounced or cross-departmental knowledge transfers. The GASAG Group, which has an organizational layout typical for medium-sized enterprises in Germany, has been and still is confronted with these challenges as well. In order to cope with them, the GASAG Group decided to work on company culture as well as develop an open and innovative mindset, leading it to join the research project ICU in 2017.

The aim of the article is to describe the approach taken by ICU from the practical, company perspective of the GASAG Group and to map out identified success factors as well to provide general recommendations for the implementation of Internal Crowdsourcing in a business environment.

The Living Group Works Council Agreement as Social Innovation: Internal Crowdsourcing in the GASAG Group

Andreas Otte, Welf Schröter, Ingo Breite, Frank Gerth, Sylvia Laur, Volker Ost, Can Sekertekin, Andreas Tabor, Marco Wedel and Hannah Ulbrich

Shortly after the formal launch of the ICU project in the summer of 2017, representatives from the group works council of the GASAG group sat down with the trade union network Forum for the Social Forms of Technology, the FST, to start up an independent practical initiative to examine the topic of Internal Crowdsourcing to be implemented soon after. In 2018, a model works council 
agreement between the group workers' council and the management was agreed, henceforth providing a framework for the IC procedure in the GASAG Group. The aim of the agreement was to serve as a template for the introduction of Internal Crowdsourcing in other companies and industries. A special feature of the agreement is the so-called 'living' group works council agreement. The following article analyses its significance and provides a translation by reproducing wording of the agreement.

\section{The Use of Internal Crowdsourcing for Qualification and Competence Devel- opment in Organizations}

André Uhl and Edgar Göll

This article deals with the question of how Internal Crowdsourcing can be used as a tool to support the development of employee qualification and competence in organizations. In the first chapter, the current state of the competence research is examined. A paradigm shift from 'qualification and professional development' towards 'competences' and the implications of this for the concept are described. Chapter "An Introduction to Internal Crowdsourcing" deals with the analyses and work on the subject of competence acquisition and development, including considering the results of two interview series and two workshops. In chapter "Managing the Crowd: A Literature Review of Empirical Studies on Internal Crowdsourcing", the authors present a combined and practical approach to support competence development through Internal Crowdsourcing in organizations. Finally, the last chapter sums up main results and perspectives for competence development through a combination of virtual and face-to-face working processes.

Power to the Network: The Concept of Social Business and its Relevance for IC Christian Zinke-Wehlmann, Julia Friedrich, Vanita Römer

The concept of IC places a focus on the employees, in their potential role as crowdsourcees, campaign owners or initiators. This reflects the emancipatory and participatory principle that goes hand in hand with the concept of social business. The basic idea of social business is not to link the business success of a company exclusively to its management capabilities or its business plan but to understand and value the individual stakeholder as part of a successful enterprise network. For social business, value is not exclusively understood as business value; rather, the perspective is expanded to include social added value, in the sense that the value of the work for the employee, society or the environment is considered as an indirect corporate goal. Thus, social business is defined as a framework or strategy that uses digital social networks (enterprise social networks) with the primary goal of generating social, ecological and economic benefits. This article introduces the social business reference model, which supports the adoption and implementation of the outlined strategy and contrasts it to the IC model in order to identify the strengths as well as the weaknesses of both models. 
Acknowledgements The goal of this book is to advance the state of Internal Crowdsourcing theory and its application knowledge. We invite the reader to examine the deductions presented here and to reflect upon their strengths and limitations. Since it is the ideal of science to be selfconsciously error seeking and thus self-correcting (Sabatier 2007, p. 5), we hope that this contribution acts as an impulse to set in motion a constructive scientific discourse. We are sure that it is a helpful contribution towards the good application of IC in companies. To enable the best possible transfer of knowledge, we are very happy to present this volume as an open access publication. This is only possible due to the generous financial support of the Open Access Publication Fund of TU Berlin. Thank you to Elena Di Rosa and Dagmar Schobert of the Publication Fund of the University Library of TU Berlin. We would also like to thank the authors of this book, without whose contributions the production of the anthology would have been impossible. In the end, we wish the reader an insightful and interesting read and look forward to further exciting debates and discoveries.

\section{References}

Bundesministerium für Bildung und Forschung (BMBF) (2015) Bekanntmachung. https://www. bmbf.de/foerderungen/bekanntmachung-1017.html

Byrèn E (2013) Internal crowdsourcing for innovation development - how multi-national companies can obtain the advantages of crowdsourcing utilising internal resources. Sweden: Department of Technology Management and Economics. http://publications.lib.chalmers.se/records/ fulltext/181969/181969.pdf

DGB Bundeskongress (2014) Leitlinien guter digitaler Arbeit. https://innovation-gute-arbeit.verdi. de/++file++53db58e16f684449d10003e0/download/Antrag\%20Gute\%20Digitale\% 20Dienstleistungsarbeit\%202014.pdf

Enquete-Kommission Internet und digitale Gesellschaft (2013) Leitlinien für eine gute digitale Arbeit. In: Achter Zwischenbericht, Wirtschaft, Arbeit: Green IT, 13.03.2013, http://webarchiv. bundestag.de/cgi/show.php?fileToLoad=2944\&id=1223

Keinz P (2015) Auf den Schultern von ... Vielen! Crowdsourcing als neue Methode in der Neuproduktentwicklung. Schmalenbachs Zeitschrift für betriebswirtschaftliche Forschung 67 (1):35-69. https://doi.org/10.1007/BF03372915

Melzer A, Heim Y, Sanders T, Bullinger-Hoffmann AC (2019) Zur Zukunft des Kompetenzmanagements. In: Bullinger-Hoffmann AC (ed) Zukunftstechnologien und Kompetenzbedarfe. Kompetenzentwicklung in der Arbeitswelt 4.0. Springer Nature, Berlin, pp 11-26

Metzger M (2016) Organisationsentwicklungsmaßnahmen in der strategischen Personalplanung von Schlüsselkompetenzen. Igel Verlag RWS, Hamburg

Pohlisch J (2019) Bericht - Innovationsaktivitäten Deutscher Unternehmen. Technische Universität Berlin, Fachgebiet Innovation Economics, Berlin. https://tubcloud.tu-berlin.de/s/ 2m2BzwNyR3T9s8a\#pdfviewer. Zugegriffen am 10.10.2019

Sabatier PA (ed) (2007) Theories of the policy process, 2nd edn. Westview Press, Boulder, Colo

TransWork (2017) Förderschwerpunkt. https://www.transwork.de/index.php/foerderschwerpunkt/

Wedel M (2016) The European integration of RES-E promotion: the case of Germany and Poland. Springer Fachmedien Wiesbaden, Wiesbaden

Wegerich C (2015) Strategische Personalentwicklung in der Praxis. Instrumente, Erfolgsmodelle, Checklisten, Praxisbeispiele, 3rd edn. Springer, Berlin. https://doi.org/10.1007/978-3-66243699-8

Zhu H, Djurjagina K, Leker J (2014) Innovative behaviour types and their influence on individual crowdsourcing performances. Int J Innov Manag 18(06):1-18. https://doi.org/10.1142/ S1363919614400155 
Zhu H, Sick N, Leker J (2016) How to use crowdsourcing for innovation?: A comparative case study of internal and external idea sourcing in the chemical industry. In: Kocaoglu DF (ed) Technology management for social innovation: PICMET'16: Portland international conference on management of engineering and technology: Proceedings. IEEE, Piscataway, NJ

Zuchowski O, Posegga O, Schlagwein D, Fischbach K (2016) Internal crowdsourcing: conceptual framework, structured review, and research agenda. J Inf Technol 31(2):166-184. https://doi. org/10.1057/jit.2016.14

Hannah Ulbrich holds a Degree in Sociology (Dipl. Soz.-Bielefeld/Berlin) and is a Senior Researcher at the Department of Vocational Education/Technology and Participation at the Technical University of Berlin. There, she is the project leader of the BMBF- and ESF-funded research project 'ICU-Internal Crowdsourcing in Companies'. In addition to her work as a project manager, she is a scholarship holder of the Berlin Professional School of Economics and Law where she is currently completing a part-time MBA programme. Her research focus is on Entrepreneurship and Innovation, New Work and Agility and Digital Transformation and Leadership.

Dr. Marco Wedel is a Political Scientist (Dipl.rer.pol., Dr. phil.) and Senior Researcher at the Department of Vocational Education/Technology and Participation at the Technical University of Berlin. In addition to study visits in Boston, Constance and Berlin, he has worked in the Energy Sector (BASF) and in Science Management (Falling Walls Foundation), among others. His current research activities focus on the topics 'Future of Work', Entrepreneurship, Digitalization and Media Competence. His long-term research focuses on European Integration, Democratic Competence and Sustainable Development. Marco Wedel is co-editor of the science journal 'Innovation: The European Journal of Social Science Research'.

Prof. Dr. Hans-Liudger Dienel is a professor for Vocational Education/Technology and Participation at the Technical University of Berlin. He is Dean of the School of Education, Head of a Masters' Programme in Science Management and of an MBA in Sustainable Mobility Management. Prof. Dienel is the Managing Director of the nexus Institut für Kooperationsmanagement $\mathrm{GmbH}$, which designs participation processes in politics and business. After studying Mechanical Engineering (Dipl.-Ing.), History, Philosophy and Sociology (M.A., Dr.phil.) in Hanover, Washington and Munich, Prof. Dienel worked at the Research Institute of the Deutsches Museum in Munich before he became Head of the Center for Technology and Society at the TU Berlin. Prof. Dienel conducts research on participation processes and is a member of the VDI Advisory Board for Society and Technology, the Steering Committee of the Citizen Participation Network and the Steering Committee of the international Democracy R\&D network.

Open Access This chapter is licensed under the terms of the Creative Commons Attribution 4.0 International License (http://creativecommons.org/licenses/by/4.0/), which permits use, sharing, adaptation, distribution and reproduction in any medium or format, as long as you give appropriate credit to the original author(s) and the source, provide a link to the Creative Commons licence and indicate if changes were made.

The images or other third party material in this chapter are included in the chapter's Creative Commons licence, unless indicated otherwise in a credit line to the material. If material is not included in the chapter's Creative Commons licence and your intended use is not permitted by statutory regulation or exceeds the permitted use, you will need to obtain permission directly from the copyright holder.

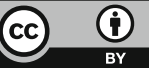

